\title{
Condition of entomophilic fauna on Hyssopus officinalis $L$. crops depending on ecotope conditions
}

\author{
Anzhelika Gorbacheva ${ }^{1 *}$, Elena Dumacheva $^{1}$, Oksana Vorobyova $^{1}$, Svetlana Korolkova $^{1}$, Sergei Filatov $^{1}$, Vladimir \\ Chernyavsky², and Daniil Koryakov $^{3}$ \\ ${ }^{1}$ Department of Biology, Belgorod State National Research University, Belgorod, Russia \\ ${ }^{2} 2$ All-Russian Research Institute of Phytopathology, 5 Ownership, Institute St.r.p, Big Vyazemy, Russia \\ ${ }^{3}$ Department of agro-industrial complex and Environmental Reproduction of the Belgorod Region, Belgorod, Russia
}

\begin{abstract}
Species diversity and number of potential pollinator species on $H$. officinalis seed crops in various ecotopes of farm fields were studied under the influence of "Bi-58 new" insecticide treatment and without preliminary treatment. The presence of 16 insect species belonging to four families of the genus Hymenoptera (Megachilida, Apidae, Halictidae and Vespidae), two families of the Diptera row (Syrphidae and Stratiomyidae) and one family of the genus Lepidoptera (Lycaenalidae) has been identified on the seed crops of $H$. officinalis. The insecticidal treatment in general did not significantly affect the total number of pollinators, but changed the species composition of pollinators and their number on the field area. As much as possible, the decrease in the prevalence and number of the Megachilida species was affected.
\end{abstract}

\section{Introduction}

Both natural vegetation and agricultural crops in agrophytocenoses are being actively studied in the Belgorod region with a view to preserving the biological diversity of flora and fauna $[1,2,3,4,5]$.

Hissopus officinalis $\mathrm{L}$. in recent years has become a popular melliferous culture in the Belgorod region. It is an etheromasliac plant with branched tetrahedral straight stems, $30-50 \mathrm{~cm}$ tall. It has small lancet-shaped leaves arranged accumbent, and bright irregular labiate flowers. The species is grown as a medicinal and etheromasliac plant. It is widely used in the food industry and perfumes, and is an excellent meliferous plant $[5,6,7]$.

Hyssop is highly drought resistant, so the plant is capable of growing on Cretaceous slopes. It prefers open, moderately wet places. H. officinalis L. in addition to experiencing dry periods, has good cold resistance, and has therefore become common as a cultural plant in many regions of the Russian Federation $[1,7,8]$.

In order to increase the yield of H. officinalis seeds, it is necessary to know not only the biology of these crops, but also the morpho-biological characteristics of pollinators $[9,10]$.

The aim of the work is to study the species diversity and number of species - potential pollinators on $H$. officinalis seed crops in various ecotopes under the influence of insecticide treatment.

\section{Material and methods}

\footnotetext{
* Corresponding author: gorbacheva@bsu.edu.ru
}

Research was carried out in the Belgorod region. Belgorod region is located within the Central Russian Upland and is part of the Central Federal District of the Russian Federation. The region has little water territory of the Russian Federation, as there is only $1 \%$ of its area containing water resources. The region is subject to erosive processes $[11,12]$.

The climate is quite soft. An average annual air temperature in the north of the area is $4.5^{\circ} \mathrm{C}$. Temperatures in winter can reach $-36^{\circ} \mathrm{C}$, but such temperatures are short and only hold for a few days. The average winter temperature is usually $-7.9^{\circ} \mathrm{C}$ to $-9.3^{\circ} \mathrm{C}$. Summer is rather warm, with an average monthly temperature of $+22^{\circ} \mathrm{C}$. The recent years have seen significant rises in summer temperatures reaching a maximum of $+41^{\circ} \mathrm{C}$.

The research of entomofauna of entomophilic plants was carried out in the last decade of July - the first decade of August 2017-2019 in Chernyanski and Novooskolski districts of the Belgorod region. The species composition of $H$. officinalis pollinators and its variation depending on the level of insecticidal load were studied. The insect collection was carried out on crops, treated with insecticides and fields free of these poisons (control fields) according to standard procedures [13, 14, 15].

In total, 16 fields were selected for study in Chernyanski and Novooskolski districts of the Belgorod region, where 20 times repeated analysis of species composition and number of insect species - potential pollinators of crops was carried out. The insect collection was carried out in sunny windless weather with an ambient temperature of $+27^{\circ} \mathrm{C}-29^{\circ} \mathrm{C}$. The humidity of the air was not different from the average summer data. 
Treatment of $H$. officinalis L. seed crops was carried out with the preparation "Bi-58 new" at a dosage of $1.2 \mathrm{l} / \mathrm{ha}$ in the budding phase. The preparation penetrates into the growing parts of the plants, into the flowers and weeds, which protects against pests the plant itself [16].

The results were processed by methods of variation statistics using Excel 7.0 and Statistica 6.0 computer programs. We took changes for statistically significant level at $\mathrm{p} \leq 0.05$ [17].

\section{Results and discussion}

H. officinalis culture is a relatively new in the region, the ecological trophic chains of its nutrition are not yet closed, and the essential oils and characteristic smell contained in the plants deter most potential pests, then mass lesions of the hyssop were not observed at the time of research. The treatment with $H$. officinalis was carried out with herbicides at the end of May to prevent crop clogging by weed vegetation species, and with insecticides at the end of July to prevent crop seed eating by pests.

Pollinalis insects, pests and entomophages were present in the field collections from $H$. officinalis L. crops. Pollinator insects are represented by three families Hymenoptera, Diptera and Lepidoptera.

Insect species are pests: Tettigonia viridissima and Etiella zinckenella $T r$. The E. zinckenella butterfly likely acts as a pollinator insect. Vaness acardui has the same meaning. Butterflies are classified by us as possible pollinators, whereas their larvae affect plants.

The entomophages in the coenopopulation of the hyssop were Chrysoperla carnea, Carabidae and Mantisreligiosa.

A rather high number of pollinators in the fields sown with medicament hyssop was observed until the end of August, while its flowering in the climatic conditions of the Belgorod region may continue until September.

$H$. officinalis' main pollinator was $M$. rotundata, whose occurrence was $5 \pm 0.15$ copies per $1 \mathrm{~m}^{2}$.

In the study of fees obtained from treated and untreated insecticide fields $H$. officinalis found a decrease in the total number of pollinator insects - $47.4 \pm 0.52$ samples $/ 1 \mathrm{~m}^{2}$ in treated fields relative to $53,7 \pm 0.12$ samples $/ 1 \mathrm{~m}^{2}$ in the untreated fields.

In addition, there was a sharp of $50 \%$ decrease in the species composition of entomophilic fauna: if 16 species of pollinators were detected in the untreated fields, only 7 species were found in the treated fields. In particular, not found: $M$. rotundata, Xylocopa valga, Bombus pascuorumi, Bombus fragrans, Rhophites canus, Eristalis tenax and Polyommatu sicarus.

Despite the fact that insecticide was used mainly for control of repeina larvae, imago of this species was present in entomological collecting and after treatment. Data on the assessment of the biodiversity of pollinators in hyssop crops are presented in the table 1 .

The table shows that the species density of the control sites is significantly higher than in insecticide treated fields (1.8 times), i.e., the species diversity decreased. The same is confirmed by the Menhinick index, which decreased 1.6 times, confirming the decrease in the number of species in the treated territories.

In fields that were not insecticidal treated as in hyssop crops, and on lucerne crops, the dominant species was the lucerne leaf-cutting bee. Its occurrence on hyssop crops was $5,0 \pm 0.11$ samples $/ 1 \mathrm{~m}^{2}$.

As a result of the treatment of the seed crops of the common hyssop with insecticide, A. mellifera was the main likely pollinator (by numerical superiority) from the caught species. The total number of species on treated common hyssop crops in the both districts of the region was 303 samples and the occurrence in an average of $3,0 \pm 1,2$ samples $/ 1 \mathrm{~m}^{2}$.

During the research, a special attention was paid to the intensity of insect work depending on the location of the fields. Thus, in the fields that were located near the bee farm, the attendance of hyssop flowers by bees was significantly higher than in the areas in the center of the field. A certain negative role was played by the process and the distance of plants from the edge of the field (i.e., from natural biocenoses) - the further away, the flowers of the hyssop were less often visited by the bees.

More uniform years of pollinator insects have been observed in the insecticide untreated fields. A rather high number of insects were observed on test sites at a distance of $150 \mathrm{~m}$ (in all cases) and $250 \mathrm{~m}$ from the edge of the field (if there are a number of bee farms). After a treatment of the fields with the preparation "Bi-58 new" the mass collections of entomophilic insects were noted only on the edge of the field and at a distance not exceeding $50 \mathrm{~m}$ from natural biocenoses. This may indicate that there are no long-range pollinators in the treated fields, such as humble-bees or lucernous leafcutting bees. The remaining possible pollinators do not fly so far from natural lands and their lodgments.

The rarest species in the insecticide-treated fields of H. officinalis was the Myiatropa florea (Myathropa florea). Its occurrence in terms of the total area was only $0,1 \pm 0.01$ sample $/ 1 \mathrm{~m}^{2}$.

Table 1. Pollinator entomofauna biodiversity indices of $H$. Officinalis

\begin{tabular}{|c|c|c|c|}
\hline $\begin{array}{c}\text { Studied } \\
\text { options }\end{array}$ & Species density & $\begin{array}{c}\text { Menhinick } \\
\text { index }\end{array}$ & $\begin{array}{c}\text { Berger- } \\
\text { Parker } \\
\text { index }\end{array}$ \\
\hline $\begin{array}{c}\text { Fields } \\
\text { without } \\
\text { insecticidal } \\
\text { treatment }\end{array}$ & $1,63 \pm 0,08^{*}$ & $0,33 \pm 0,02 * *$ & $0,05 \pm 0,01$ \\
\hline $\begin{array}{c}\text { Fields } \\
\text { processed } \\
\text { by an } \\
\text { insecticide }\end{array}$ & $0,92 \pm 0,04^{*}$ & $0,21 \pm 0,01^{* *}$ & $0,06 \pm 0,01$ \\
\hline
\end{tabular}

Note - *differences are significant at $99 \%$ significance level; ** - differences are significant at $95 \%$ significance level; tst $0.05=3,18$, tst $0.01=5,84$

By calculating the Jacquar index for potential pollinator species of entomophilic crops in the both areas studied, it was found that pollinator faunas in Chernyansky and Novooskolsky areas are identical (the Jacquar index is 1). 
According to our observations, both the number of insect copies and their species composition decreased in collections obtained after insecticidal treatment of hyssop fields. However, after calculating the Jacquar index for processed and untreated $H$. officinalis fields, the value was 0,7 . This points to two possible options:

1) it can be a rapid recovery of entomophilic fauna;

2) indicates resistance of certain species to insecticidal treatment. Both ultimately ensure that both the numbers of potential pollinators and their species diversity are preserved.

\section{Conclusion}

The study of species diversity and number of species potential pollinators on the seed crops of $H$. officinalis revealed the presence of 16 insect species belonging to the four families of the unit Hymenoptera (Megachilida, Apidae, Halictidae and Vespidae) two families of the unit Diptera (Syrphidae and Stratiomyidae) and the family of the unit Lepidoptera (Lycaenidae и Nymphalidae) on a given entomophilic culture.

\section{References}

1. V.I. Chernyavskikh, Farming. 6, 18 (2009)

2. E.V. Vishnevskaya, T.B. Klimova, I.V. Bohomazov, E.V. Dumacheva, O.V. Yakovenko, Mediterranean Journal of Social Sciences. 6, 561 (2015)

3. E.V. Dumacheva, V.I. Cherniavskih, E.I. Markova, T.B. Klimova, E.V. Vishnevskaya, Research Journal of Pharmaceutical, Biological and Chemical Sciences (2015)

4. E.V. Dumacheva, V.I. Cherniavskih, V.K. Tokhtar, L.A. Tokhtar, T.A. Pogrebnyak, E.N. Horolskaya, A.A. Gorbacheva, O.V. Vorobyova, T.N. Glubsheva, E.I. Markova, S.V. Filatov, International Journal of Green Pharmacy. 11, 476 (2017)
5. E.V. Dumacheva, V.I. Cherniavskih, A.A Gorbacheva, O.V. Vorobyova, Z.A. Borodaeva, E.N. Bespalova, L.R. Ermakova, International Journal of Green Pharmacy. 12, 354 (2018)

6. O.V. Degtyar, V.I. Chernyavskikh, Herald of Nizhniy Novgorod University Named After Lobachevsky. Biology. 2, 254 (2004)

7. V.I. Cherniavskih, E.V. Dumacheva, A.A. Gorbacheva, O.V. Vorobyova, L.R. Ermakova, International Journal of Green Pharmacy. 12, 433 (2018)

8. F. Dikmen, Turkish Journal of Zoologi. 4, 537 (2011)

9. R.B. Kozin, Beekeeping. 10, 20 (2011)

10. E.V. Dumacheva, V.I. Chernyavskikh, Fodder production. 2, 34 (2012)

11. E.V. Dumacheva, V.I. Chernyavskikh, Fodder production. 4, 7 (2014)

12. E.V. Dumacheva, V.I. Chernyavskikh, Fodder production. 2, 23 (2014)

13. K.K. Fasulati, Field study of terrestrial invertebrates (1971)

14. Y.A. Pasenko, Ecology. 1, 89 (1972)

15. I.B. Popov, Plant protection from harmful organisms. 216 (2019)

16. B.A. Alexander, C.D. Michener, Univ. Kansas Sci. Bull. 11, 377 (2015)

17. B.A. Dospekhov, Field experience methodology (with basic statistical processing of research results) (2012) 